\title{
Impact of Integrated Financial Management Information System on Performance of Public Institutions in Rwanda
}

\author{
Jean Bosco Harelimana ${ }^{1, *}$ \\ ${ }^{1}$ Institut d' Enseignement Superieur de Ruhengeri, Musanze, Rwanda \\ *Correspondence: Institut d' Enseignement Superieur de Ruhengeri, P.O.B. 155 Musanze, \\ Rwanda. E-mail: harelijordan@yahoo.fr
}

Received: November 2, 2017 Accepted: November 21, 2017 Published: November 24, 2017

doi: 10.5296/erm.v3i1.12230 URL: https://doi.org/10.5296/erm.v3i1.12230

\begin{abstract}
A study of assessing the contribution of adoption of IFMIS on performance of Public institutions in Rwanda was carried out under the period 2012-2016. The study is descriptive in nature where raw data was used. Data were collected from 51 out of 197 total population sampled based on available respondents. Methods such as questionnaire, observation, interview and documents was used together both primary and secondary data. After data collection, SPSS Version 32 program was been used for gathering data and cleaning them. The Software also was used to perform statistical techniques that including percentages, mean, standard deviation, and correlation, this was helped the researcher in getting findings for the research conclusion and recommendation.

Findings revealed that IFMIS was fully adopted in MINECOFIN with mean of 4.05 indicate that respondents are strongly agree that IFMIS was adopted fully in MINECOFIN: the implementation of the system was done following all required steps, (mean of 3.86 and standard deviation of .721) and it was also increased the capacity bulding of its personnel by offering the necessary training (with mean of 4.43 and standard deviation of .7). the adoption of IFMIS helped in budgeting system (mean of 3.990, cash management (with mean of 4.15), financial reporting (with mean of 4.02) and internal control system (with mean of 4.16). This affected positively the performance of the organization where the correlation between the adoption of IFMIS and performance of MINECOFIN was .976 means the perfect correlation. By conclusion, we confirm the research of Rodin (2008) and (Diamond and Khemani, 2006), that they are significant contribution of integrated financial management information system on performance of public institutions in Rwanda, where it generates timely, the accurate information for the management decision making.
\end{abstract}

Keywords: IFMIS, management, public finance, performance and Public financial management 


\section{Introduction}

Government accounting has a long history and was practiced even when there were no organized budgets. Diamond and Pokar (2006) said that the efforts in government accounting were primarily oriented to double-entry bookkeeping and there was a lack of a coherent theory. And then was a move from bookkeeping to accounting that involved the measurement and transactions. During the twentieth century further refinements were made in costs and management accounting and the accounting system as a whole developed to meet purposes that were diverse but all related to the decision making requirements of a commercial entity. These approaches have also had their impact on government accounting.

According to Ijiri (1967), accounting systems in government do not appear to have received the attention they needed or deserved. Although many reforms have been introduced to recognize problems and solve them, there are still many issues that remain to be resolved. The government accounting is still different from commercial accounting by being motivated by complying with the law and social return from the government expenditure while the commercial accounting is profit motivated. In the aftermath of the Genocide of 1994, in Rwanda there was a strong need to build Public Finance Management Systems aiming at improving the efficiency of spending of few resources as well as strengthening of Rwanda's fiscal institutions, by promoting transparency and enhancing governance. Since then progress was seen in terms of improved Public Financial Management (PFM). The Organic Budget Law (OBL) was gazette in September 2006; however, capacity building was required to ensure that the law is effectively implemented.

Before 2006 accounting and reporting was not streamlined in Government Institutions; there were no sound book keeping. Hence, there was high dependency on manual systems and process hence no efficiency and effectiveness into different processes of Government institutions one would expect to see much. Also there was a poor transparency and accountability which leading to corruption and fraud.

Also, Manual systems and processes were used into different government agencies. In early 2007, the Government of Rwanda, with the assistance of the international auditing firm Price Waterhouse Coopers, produced the country's first set of consolidated accounts in line with constitutional requirements. Also, the GoR has started developing the capacity of the Accountant-General's office and the Finance Departments of different budget agencies, so that they are able to produce final accounts in subsequent years. A quarterly cash flow plan system was adopted in January 2006 and this sets the spending limit of budget agencies. A Single Treasury Account has been established and all government agencies are subject to a system of zero balance drawing bank Accounts, (Chêne, 2009).

According to the Mohammed Aminatu (2015), in Korea University in his research on Impact of Integrated Financial Management System on Economic Development said that "The Integrated Financial Management System (IFMS), which was introduced to developing countries in the 1990s, is one way to manage finance effectively. However, the implementation was a failure in most countries due to factors such as a lack of capacity building and over ambitiousness of these nations". Rwanda has recently gone back to this 
system, naming Integrated Financial Management System This study looks at the Contribution of IFMIS on performance of public institutions by making use of both qualitative and quantitative data over the last five years by the Ministry of Finance and Economic Planning. This study looks at the Contribution of IFMIS on performance of Public Finance Management.

According to MINECOFIN (2006), to guide end users of the IFMIS Integrated Financial Management information system IFMIS is a government software that helps to consolidate the information related to the assets and funds of Government inflows and outflows of it. The owner of the IFMIS is the Government of Rwanda is the web based software that simplified the workload of the Staff of the Government agencies in their working environment. This system Designed to facilitate the government activities like Planning and Monitoring Budget Preparation, Budget Execution, Consolidation.

Evolution of this software in Rwanda started an IFMIS is an integrated software that can support government planning, budgeting, accounting, and reporting. Enable Public institutions to record the information related to the use of Public Funds Though the IFMIS you Can get all Government Expenditures and Revenues, Hardware, software, data, people procedures are combined to form an information in this system, (MINECOFIN, 2011).

Generally, the objective of implementing Integrated Financial Management Information System (IFMIS) is to increase the effectiveness and efficiency of state financial management and facilitate the adoption of modern public expenditure practices in keeping with international standards and benchmarks. Much of the work in automating IFMIS systems has focused on financial management information system, including general ledger, accounts payable, accounts receivable, procurement, payroll, asset management, debt management, budgeting. Other points in this regard were to start from where you are in terms of PFM system development, rather than from where you want to be and also to recognize that not everything may need to be automated. As IFMIS systems evolve, the needs will change, so the scope of the automation can be expanded. Given the rapid change in technology, it may not be feasible to plan all of these potential needs or IT options in advance, (Bartel, 2009).

Governments in developing countries are increasingly exploring methods and systems to modernize and improve public financial management. For example, over the years, there has been an introduction of the IFMIS as one of the most common financial management reform practices, aimed at the promotion of efficiency, effectiveness, accountability, transparency, security of data management and comprehensive financial reporting. The scope and functionality of an IFMIS varies across countries, but normally it represents an enormous, complex, strategic reform process, (Husnan \& Pudjiastuti, 2006).

This follows a growing interest in the quality of public sector financial management in developing countries by the donor community. In the early years after the fall of the Berlin Wall in 1989, interest in the state affairs was limited, but following the World Bank's report, the role of the state became increasingly prominent in development efforts, and particularly in the drive against poverty (World Bank, 2008). As a result, consultants and other advisors of governments in Africa started toying with idea of the introduction of modern information 
technology, the Integrated Financial Management Information Systems -IFMIS, (World Bank, 2004).

Financial performance is concerned with the ethical conduct with which public institutions carry themselves while handling public finances. Following the implementation of the Integrated Financial Management Information Systems by the Government of Rwanda, this study seeks to answer the question; does electronic transaction processing play a role in enhancing financial performance in the public institutions? Government financial management performance is concerned with financial management of public Institutions both (Central Government and local government).

There is broad agreement that a fully functioning IFMIS can improve governance by providing real time financial information that financial and other managers can use to administer programs effectively, formulate budgets, and manage resources. Sound IFMIS systems, fixed with the adoption of centralized treasury operations, can not only help developing country governments gain effective control over their finances, but also enhance transparency and accountability, reducing political discretion and acting as a deterrent to corruption and fraud (Cendon, 1999).

According to Oliga (1982), upgraded financial management systems will not work, nor will the benefits materialize, without attention to the human factor. In financial management three key groups can be identified: those who offer the system, those who receive services from the system "client", and those who use the outputs of the system "users" referred to end users throughout this research. Financial management systems can be really useful only if there is a skilled class of users in a position to use the results. Indeed, financial management systems have to be adapted specifically to achieve this, and often users have to be trained to get maximum benefit from financial systems. This study examined the perceptions of those that use the integrated financial management information system in public sector day to day Activities especially in in Ministry of finance and Economic planning.

IFMIS refers to computerization of public expenditure management processes including budget formulation, budget implementation and accounting with the help of a fully integrated system for financial management of the line ministries and other spending agencies. Diamond $\&$ Khemani (2005) noted that in most developing countries, budget execution and accounting processes were or are either manual or supported by very old and inadequately maintained software applications.

They said that this has had un favorable effects on the functioning of their public expenditure management (PEM) systems and that the consequent lack of reliable and timely revenue and expenditure data for budget planning, monitoring, expenditure control, and reporting has negatively impacted budget management resulting in a poorly controlled commitment of government resources, often leading to a large build-up of arrears; excessive borrowing, pushing up interest rates and assembling out private sector investment; and misallocation of resources thus undermining the effectiveness and efficiency of service delivery. 


\section{Objectives}

The general objective of this study is to assess the influence of adoption of IFMIS on performance of public institutions in Rwanda specifically:

1. To assess the determinants of IFMIS in MINECOFIN,

2. To analyze the indicators performance in MINECOFIN,

3. To measure the relationship between the IFMIS determinants and performance indicators of MINECOFIN.

\section{Literature Review}

According to Edwin R. B. (2008), IFMIS can be defined as an integrated software that can support government planning, budgeting, accounting, and reporting. It enables Public institutions to record the information related to the use of Public Funds, though the IFMIS you can get all Government Expenditures and Revenues, Hardware, software, data, people procedures are combined to form an information in this system, IFMIS "a financial management information that tracks financial events and summarizes financial information".

The IFMIS implementation requirement in Rwanda is originated from design of The Ministry of Finance and Economic Planning ICT Master Plan 2001-2005 that highlighted gaps and weaknesses within the SIBET system that was in use, the master plan was proposing development of different modules comprising:

Accounting management, Revenue management, Asset management etc and establishment of interfaces with the National Bank payment information system, Rwanda Revenue Authority and the Ministry of Labour for payroll and human resource management modules.

The failure to implement the accounting module which comprises the core components of IFMIS is mainly attributed to the lack of proper sequencing of financial procedures, legal framework and software customization or development. Currently the Ministry of Finance is reviewing the IFMIS implementation process and the current research aim to enhance that process by identifying success factors that are relevant to Rwandan case of IFMIS implementation, (Gauld, Shaun \& Tony, 2006).

Various studies having been conducted both internationally and locally on IFMIS and procurement performance, Nyabuto (2009) undertook a Survey of the Extent of Implementation of Integrated Financial Management Information System as a tool for sustainable financial management in government. The study revealed that there was resistance in the Ministries for the use of IFMIS.

Kakwezi and Nyeko (2010) conducted a study on procurement processes and performance: Efficiency and effectiveness of the procurement function in Uganda and found out that other than financial measures, non- financial measures also contribute significantly in the procurement process and performance. 
Spriano (2013) carried out a study on the successes and failures of e-Government projects in Developing Countries: a case study of Zambia. The results of the study indicted a rating score of 55.1 based on Heeks 100 point scale implying a mighty fail totally or partially. In addition the awareness of the e-government projects was found to be inadequate. Mbae (2014) investigated the impact of public procurement law on the performance of Machakos county government. The study established that political forces, unethical practices, lack of transparency and accountability and dishonesty among procurement officers have affected procurement processes.

Mauki (2014) conducted a study on factors influencing Implementation of Public Procurement and Disposal Act in Kenyan Judiciary from regions perspective. The findings revealed that accountability, ICT adoption, stakeholders' ethics and staff competence influenced implementation of Public Procurement and disposal Act at Kenyan Judiciary.

In a research by Kimwele in 2011, he found out that the level of awareness by employees of the Government ministries was $100 \%$. He also found out that $70 \%$ of the departments used IFMIS. $73 \%$ of the respondents to the research questions said that there was sabotage of IFMIS. 37\% of the respondents said that IFMIS supported proper planning of work. There is a great percentage of abuse of the system but IFMIS offers security to personal data (Kimwele, 2011). In his research, Kimwele put forward several factors which are important in IFMIS implementation.

The study by Dener and Young (2013) attempted to explore the effects of IFMIS on publishing open budget data and identify potential improvements in budget transparency, and provide some guidance on the effective use of IFMIS platforms to publish open budget data. The study identified $20 \mathrm{key}$ and 20 informative indicators drawn from the public finance websites of 198 economies to assess the status of government websites for publishing open budget data from IFMIS. The study established that despite the widespread availability of 176 FMIS platforms used by 198 governments around the world, good practices in presenting open budget data from reliable IFMIS solutions are highly visible in only 24 countries (12\%).

Barry (2001) investigated the guidelines for public expenditure management in the government ministries. The study established that the level of complexity of IFMIS is much higher than other ICT-based government reforms due to inherent complication of public financial management system. It involves not only ministry of finance but also all line ministries and other multiple spending units. However, integrated public financial management system is quite a challenging task and requires multiple conditions to be satisfied for successful implementations of long term sustainability. The study recommended that the introduction of IFMIS system should not just be seen as a technology fix, since simply automating tasks that did not need to be carried out in the first place rather IFMIS implementation should be seen as a public financial reform that affects how things are done across government ministries and parastatals.

Muigai (2012) investigated the effect of integrated financial management information systems on the financial management of public sector in Kenya: a case of the Kenyan ministries. The study covered 42 government Ministries in Kenya where 30 accountants 
involved in the use of Integrated Financial Management Information Systems were surveyed and data collected using both primary and secondary questionnaires and review of economic survey and statistical abstract. The study found out that IFMIS has greatly contributed to improvement in financial management in Kenya.

Chebet (2013) also investigated the critical success factors in the implementation of the re-engineered integrated financial management information system in government ministries, Kenya. The researcher used survey research design. Stratified sampling technique was used to divide the population into three strata: finance officers, ICT officers and Key system users and obtained a sample size of 54. The study collected primary data through the use of a questionnaire. The study established the following 9 group of factors as being critical in the implementation of the re-engineered IFMIS: user involvement in the process and clear procedures for recruitment and risk management; proper management of resources; top level cash management and budgeting systems; good communication strategies among stakeholders, team spirit and good support teams, skilled team; clear and properly set goals and objectives; appropriate infrastructure; set timelines for capacity building and achievement of goals and objectives; and involvement of competent firms in the project. In addition, co-operation among departments, the availability of experts, adequate learning materials and adequate pre-testing of the system were found to have contributed to the success of the implementation.

Chuma (2014) investigated the integrated Financial Management Information System and Its Effect on Cash Management in Eldoret West District Treasury, Kenya. The purpose of this study was to investigate the effect of IFMIS on cash management practices in the public service. The study was based on descriptive survey research design was employed. The study focused on70 staff and top management at the Eldoret West District treasury. Questionnaires and interview schedules were used to collect primary data. Data was analyzed using descriptive statistics, regression and correlation. Study findings showed that reliability of IFMIS, Flexibility of IFMIS positively affect cash management. The findings also showed that a reliable system is basically one that is accurate, timely, complete and consistent in collection of information and the infrastructure which supports the IFMIS is supposed to be secure from destruction, corruption, unauthorized access and breach of confidentiality so that there is efficient cash management.

Kibui (2013) investigated financial literacy and financial management of the youth enterprise development fund in Konoin constituency Kenya. A cross sectional descriptive survey technique was adopted to find out the financial literacy and financial management of the youth enterprise development fund in Konoin constituency. A representative sample of 250 respondents was selected using random sampling technique. The study used primary data which was collected from the respondents using a detailed questionnaire which had both open ended and close ended questions. Data was then analyzed by using regression analysis and descriptive statistics which was presented using mean, correlation, standard deviation and percentages. The analysis was then visually displayed using graphs, frequency tables and charts. 
Based on the findings financial literacy had a direct relationship with financial management with many youth lacking the basic skills in financial planning practices. The level of financial literacy among the youth was low which was attributed by low level of financial knowledge, less exposure to managing finances and also their education levels. Diamond and Khemani (2008) in their study on introduction to financial management information systems in developing countries further mention that all manner of reports can be generated; balance sheets, sources and uses of funds, cost reports, returns on investment, aging of receivables and payables, cash flow projections, budget variances, and performance reports of all types. Some systems have libraries consisting of hundreds of standard reports.

Managers can use this information for a variety of purposes; to plan and formulate budgets; examine results against budgets and plans; manage cash balances; track the status of debts and receivables; monitor the use of fixed assets; monitor the performance of specific departments or units; and make revisions and adjustments as necessary, to name a few. Reports can also be tailored to meet the reporting requirements set by external agencies and international institutions like the International Monetary Fund (IMF). Hashim (2001) investigated core functional requirements for fiscal management systems. The study used primary data which was collected from the respondents using a detailed questionnaire which had both open ended and close ended questions. The study established that financial management information systems are implemented and used successfully almost in all time in the commercial world. It was also established that the IFMIS system control ensures that before a purchase is committed to, there is sufficient cash allocated for the expense and the allocation matches the appropriate budget.

As IFMIS was implemented in Rwanda for wider reforms aimed at enhancing and harmonizing budget preparation, execution, and financial management and reporting across government agencies. Smart FMS is an Integrated Financial Management Information System (IFMIS) used throughout government for budget execution. During budget preparation, budget data is entered into the system, and during execution, spending commitments are recorded in Smart FMS to track execution (MINECOFIN, 2011). It focuses on alleviating challenges from an operational perspective. It is not and cannot be a solution for every problem associated with budget formulation or execution. This study sought to investigate the relationship existing between the IFMIS and performance of Public Institutions in Rwanda. While a lot of researches have been carried out in establishing the effect of IFMIS and perception of end users in local Government, but none of studies has effectively synthesized IFMIS specifically with performance of public institution in Rwanda. Hence, this research intends to bridge this gap by trying to study and analyze the relation between IFMIS and performance of public institutions in Rwanda.

\section{Research Methodology}

This section is an assessment and exploration of how the research will be conducted. It explains the case study profile, the research design and methodologies that are expected to be used in the research process, which is the collection of data. The section reflects the whole 
process of research in terms of all methods and techniques to achieve the objectives of the study. It provides details of the research design of the study, sampling, target population, methods of sampling and data collection.

\subsection{Data}

To provide the solution reliably to the research objectives, the research was made to be descriptive one where quantitative and qualitative data collected to reach the objectives of this study. The data were obtained from primary and secondary sources. The primary data was collected by use of a structured interview and questionnaires and the secondary data was obtained from different data base including books, e-resources and governmental institutions reports ioncluding different reports of MINECOFIN and journals as well as websites like MINECOFIN. Secondary data was supplemented by primary data obtained through selfadministered questionnaire-based interviews. Data were collected from 197 employees of MINECOFIN where 51 were sampled based on their availabilities.

\subsection{The Sample}

A sample is a part of the target population that has been procedurally selected to represent it (Bell, 1993). The sample was composed by 51 populations of MINECOFIN employees.

\subsection{Models and Techniques}

To measure the relationship between the IFMIS determinants and performance indicators of MINECOFIN, Spearman's correlation coefficient was used to determine this relationship. The correlation was extracted using SPSS version 32.

\section{Findings and results}

\subsection{Assessment of IFMIS in MINECOFIN}

From the study findings, IFMIS role on the budgeting processes has been seen to be instrumental towards effective of public institution management practices. This study however found that IFMIS contributed towards effective management practices, (respondents show us that they are strongly agreed that IFMIS facilitate the budgeting system process: with mean of 3.99 means strong agree). Based on the positive coefficient results generated, the study shows that IFMIS and effectiveness in management practices move in the same direction and that for every unit increase in IFMIS effectiveness in management.

\subsection{Analysis of the Performance in MINECOFIN}

Based on the positive coefficient results, the study shows the variables follow each other and that for every unit increase in computerization of public institution increased with automation of services.

\subsection{To Measure the Relationship between the IFMIS and Performance of MINECOFIN}

The respondents in this study were made by IFMIS experts, Directors, Planners; Accountants 
and Budget officers. The respondents are the key players in the management of public finance management in Rwanda. As for gender distribution $58.8 \%$ of the respondents were males and $41.2 \%$ were female. This implies who important gender balance is looked after in the public finance management and more training is highly required so as to enable mostly staffs to get required knowledge in the field of public finance. The respondents has strongly agree that IFMIS has a greather positive impact on cash management (overall mean of 4.15), budgeting system, (overall mean of 3.99), financial reporting (overall mean of 4.02) and internal control (overall mean of 4.16). All those point has a greater impact of the performance of public institutions finance.

5.4 Analysis of Integrated Financial Management Information System facilitates operations in Public institutions

The first objective of the study shown that in Rwanda Local Government like Districts, before the introduction of Smart FMS; there were a number of systems which have been using to produce their Financial Statements.

In all Public institutions, users have received training on different Smart FMS modules and functionalities including Chart of Account, Accounts Payable, Budget Preparation, Cash Flow Functionality, Bank reconciliation functionality, General Ledger module as well as Revenue Management functionality. Depending to people trained in a given module or functionality, this illustrates the knowledge acquired by users per each module, the respondent have strongly agree that MINECOFIN putted in place a clear legal framework relating to accounting services (with mean of 4.35 and standard deviation of .743), solving technical challenges (with mean of 4.6 and standard deviation of .493), capacity building and training (with mean of 4.07 and standard deviation of .716) and it offered the right training regarding the implementation of IFMIS, (with mean of 3.98 and standard deviation of .677)

The research has found that all users prefer using Smart FMS than previously used software and their preference of Smart FMS compared to other software is due to the fact that it's have in built reports facilities, that Accountant doesn't take extra time to reconstruct financial Statements, and that prefer Smart FMS because the use of uniform chart of accounts facilitate accounts consolidation, that their preference vis a vis other than Software is due to the fact that it posts transactions automatically in General Ledger, that Accountant and Budget Officer participate both in the preparation of financial Statements, even that Smart FMS cannot be converted easily to Excel and all historical transactions data on unavailable on single click. A part from the features, the benefits of SmartFMS has been enumerated by users in the following percentage which highlights how SmartFMS has contributed in different Financial Management Processes.

IFMIS is used in those different processes for having efficient management. This demonstrates that IFMIS is used while processing different operations in Rwanda Local Government and helped to get how IFMIS has improved financial management within Districts since all operations are automated. They noted that IFMIS provide an automated generated document on each payment processed through IFMIS and those documents are purchase order, payment voucher, payment order and journal voucher and all respondents 
responded that IFMIS provides operation reports and those reports are statement of revenues and expenditures, statement of financial position, trial balance, general ledger, cash book and budget execution.

\section{Conclusions and Recommendations}

\subsection{Conclusion}

It is clear from the discussions above that the successful implementation of an IFMIS is a major component, if not one of the goals, of PFM reform. Although it may not fully prevent fraud and corruption in government institutions, the standardized information that management receives should assist in identifying and investigating unusual transactions or activities, which may increase Government's ability to root out corruption.

The success and sustainability of the IFMIS is dependent on a an effective sustainable strategy and the effective implementation of other PFM reforms such as a review of the country's PFM Act, review of budgeting process, development of a Standard Chart of Accounts etc. These aspects should be supported with clear political leadership and commitment and the appropriate resources, capacity building and change management strategies.

The IFMIS is considered to be the over-arching reform which aligns all other PFM processes. It gives effect to the overall objective of PFM and is a valuable tool for decision-making in the public sector. However, it is important for governments to realize that there is no "one-size-fits-all" solution where IFMIS is concerned. Each country is unique and consequently a tailored solution is required to address the specific system requirements, information needs and users.

The conclusions of the study also are drawn from the most significant factors presented in the preceding sections. The study thus concludes that there has been a moderate level of implementation of IFMIS in Government institutions. Training/capacity building, employee commitment, human resources available, top management support, technological infrastructure, governance system, reporting accountability, incentives structure and legal framework in place affect the implementation of IFMIS in Rwanda. IFMIS forms part of the financial management reform practices of developing countries globally. It holds benefits such as effective control over public finances, contributes to the enhancement of transparency and accountability and serves as a deterrent to corruption and fraud.

\subsection{Recommendations}

In order to tap the many benefits associated with adoption of IFMIS implementation this study recommends that; The National government needs to inject further support to the Public institutions with change management trainings to overcome resistance noted posing a challenge in adoption. The staffs at the institution level require an appreciation on the need for IFMIS through trainings and hand holding which can be facilitated through additional budget not available due to limited funding at institution. Now that IFMIS is already 
deployed to the institutions a lot of sensitization needs to be done to the users and all stakeholders for it to be successful.

Non-adoption has resulted to continuous manual processes at the institution level inhibiting effective service delivery, effective corporate governance from manual procurement processes, manual budgeting processes as well as un-computerized human resource management.

Clear objectives on the need to implement IFMIS need to be reframed based on the intent to increase customer satisfaction, reduce wastage, increase efficiencies and eliminate graft amongst other evils like unproductive workers. A clearer understanding on the global egovernment system trends designed to accommodate all financial transactions within the government to geared towards reducing wastage, enhanced record keeping, for planning and reduction of corruption must be emphasized.

There is need to ensure that the requisite infrastructure are in place especially in outlying areas out of Rwanda where ICT connectivity leave alone electricity availability is a real challenge. If the infrastructure cannot be put in place in the whole institution, the result will be that it will be branded as a Rwanda "project" while in the other areas manual systems continues as usual.

Further, a strong IFMIS project implementation and coordination working committee championing the counties' level implementation coordinated by a secretariat derived from the national IFMIS need to be constituted providing regular updates on implementation status and challenges met.

\subsection{Conclusion}

It is clear from the discussions above that the successful implementation of an IFMIS is a major component, if not one of the goals, of PFM reform. Although it may not fully prevent fraud and corruption in government institutions, the standardized information that management receives should assist in identifying and investigating unusual transactions or activities, which may increase Government's ability to root out corruption.

The success and sustainability of the IFMIS is dependent on an effective sustainable strategy and the effective implementation of other PFM reforms such as a review of the country's PFM Act, review of budgeting process, development of a Standard Chart of Accounts etc. These aspects should be supported with clear political leadership and commitment and the appropriate resources, capacity building and change management strategies.

The IFMIS is considered to be the over-arching reform which aligns all other PFM processes. It gives effect to the overall objective of PFM and is a valuable tool for decision-making in the public sector. However, it is important for governments to realize that there is no "one-size-fits-all" solution where IFMIS is concerned. Each country is unique and consequently a tailored solution is required to address the specific system requirements, information needs and users. 


\section{Ml Macrothink}

Enterprise Risk Management

ISSN 1937-7916

2017, Vol. 3, No. 1

The conclusions of the study also are drawn from the most significant factors presented in the preceding sections. The study thus concludes that there has been a moderate level of implementation of IFMIS in Government institutions. Training/capacity building, employee commitment, human resources available, top management support, technological infrastructure, governance system, reporting accountability, incentives structure and legal framework in place affect the implementation of IFMIS in Rwanda. IFMIS forms part of the financial management reform practices of developing countries globally. It holds benefits such as effective control over public finances, contributes to the enhancement of transparency and accountability and serves as a deterrent to corruption and fraud.

\subsection{Areas for Further Studies}

For further studies, the researcher recommends that future scholars can focus on how to establish a model for testing and evaluating the level of success in the implementation of IFMIS in the Governments institution and establishing the role of end users on the level of success in the implementation of IFMIS in the Governments institution.

With insufficient resources and time, the researcher could not cover everything concerning the topic of the study. Therefore, the researcher wishes to suggest to other researchers to carry out a study on perception of end users on IFMS even in other remaining components of government like Rwanda Central Government or Independent Development Projects.

\section{References}

Chêne, M., (2009), The Implementation of Integrated Financial Information Management Systems (IFMS), from http://www.u4.no/ helpdesk/helpdesk/query.cfm?id=196

Diamond, J., \& Khemani, P. (2006). Introducing financial management information systems in developing countries. OECD Journal on Budgeting, 5(3), 97-132. http://dx.doi.org/10.1787/budget-v5-art20-en

Diamond. J., \& Khemani, P. (1999). IFMIS in developing countries. IMF paper.

Edwin Rodin-B. (2008). Integrated financial management information systems: a practical guide. United States Agency for International Development

Kimwele, J. M. (2011). Effective Implementation of the Integrated Financial Management. London Press Ltd.

Mbae, N. (2014). Public Procurement Law and Procurement Performance of County governments in Kenya: Case of Machakos county government.

Mutui, M.F. (2014). Integrated Financial Management Information System on Procurement.

Rodin-Brown, E., (2008), Integrated Financial Management Information Systems: A practical guide, from http://pdf.usaid.gov/pdf_docs/ PNADK595.pdf

Rozner, S. (2008). Best practices in fiscal reform and economic governance. Introducing 
integrated financial management information systems, viewed 06 April 2011, from http://blog-pfm.imf.org/pfmblog/files/ifmis_bpn_web1.pdf

\section{Copyright Disclaimer}

Copyright for this article is retained by the author(s), with first publication rights granted to the journal.

This is an open-access article distributed under the terms and conditions of the Creative Commons Attribution license (http://creativecommons.org/licenses/by/3.0/). 